\title{
Individuals with Intellectual Disabilities: A Review of the Literature on Decision-Making since the Convention on the Rights of People with Disabilities (CRPD)
}

\author{
Shirli Werner, $\mathrm{PhD}^{1}$
}

\begin{abstract}
To achieve the basic human right of autonomy, individuals, including those with intellectual disabilities (ID), must be able to practice decision-making, that is, to make their own decisions and communicate these decisions to others. In support of autonomous decision-making, Article 12 of the United Nations Convention on the Rights of People with Disabilities (CRPD) stresses the right of individuals with disabilities to legal capacity on an equal basis with others. ${ }^{1}$ Supported decisionmaking approaches may aid individuals with ID in achieving this right. The question remains whether the enactment of the CRPD indeed is translated into opportunities for autonomous and supported decision-making among individuals with ID. In order to examine this question, a systematic review of bibliographic databases since 2008, when the CRPD came into force, was conducted in order to map the current state of decision-making among individuals with ID, and to identify areas in need of improvement. Twenty-seven manuscripts were reviewed, most focusing on decision-making within the fields of residential settings, health care, and sexualityrelated decisions. This review showed that difficulties in decision-making in the area of ID remain during the early years after the CRPD entered into effect. These difficulties are related to the individuals with ID themselves, to their caregivers, and to the service system. No working models on supported decision-making for this population were found. The discussion highlights the importance of developing decision-making skills among people with ID, allowing them opportunities for decision-making, training professionals in supported decision-making, and fostering the philosophy of person-centered planning.
\end{abstract}

Keywords: Intellectual disability, systematic review, decision-making, autonomy, human rights

\footnotetext{
${ }^{1}$ Lecturer, Paul Baerwald School of Social Work and Social Welfare, Hebrew University of Jerusalem, Israel.

Corresponding Author Contact Information: Shirli Werner at shirlior@mscc.huji.ac.il; Paul Baerwald School of Social Work and Social Welfare, Hebrew University of Jerusalem, Jerusalem, Israel.
} 
Suggested Citation: Werner S. Individuals with intellectual disabilities: a review of the literature on decision-making since the Convention on the Rights of People with Disabilities (CRPD). Public Health Reviews. 2012;34: epub ahead of print.

\section{INTRODUCTION}

Intellectual disability (ID) is characterized by significant limitations in intellectual functioning (i.e., IQ below 75); limitations in adaptive behavior which comprises three skills types (conceptual skills, social skills and practical skills), and it originates before the age of $18 .{ }^{2}$ Individuals with ID are in need of specialized, integrated treatment ${ }^{3}$ and are provided for by services within the health, education, and social welfare sectors. According to Article 12 of the United Nations Convention on the Rights of Individuals with Disabilities (CRPD), ${ }^{1}$ all individuals should have the right to legal capacity. ${ }^{1}$ In order to exercise this basic human right of autonomy, individuals must be allowed to make their own decisions and communicate these decisions to others. Towards this end, services must employ supported decision-making approaches, which would greatly change the way in which families, professionals, service providers, and the general community perceive and act in reference to persons with ID. The aim of the present review is to map the empirical literature on decision-making among individuals with ID since the CRPD has come into force in 2008 and learn about those areas in need of improvement.

\section{THE IMPORTANCE OF MAKING CHOICES}

Autonomy refers to an individual's capacity to govern him/herself. In order to exercise informed decisions, individuals must have the relevant information, be able to reflect on their values, desires and goals so as to affirm or disaffirm them, make intentional judgments and decisions based on them, and communicate that selection to others. ${ }^{4}$ Decision-making is a central element of self-determination, empowerment, and social inclusion for people with disabilities. Accordingly, best-practice approaches to service delivery, such as person-centered planning, place the consumer in the role of the decision-maker regarding what service support and assistance are needed and who is best suited to provide them. ${ }^{5}$ 


\section{THE CONVENTION ON THE RIGHTS OF PEOPLE WITH DIS- ABILITIES AND ARTICLE 12}

The basic human right to choice is mandatory according to the CRPD 1 which was adopted by the United Nations in 2006 and came into force internationally in 2008. ${ }^{6}$ To date, 153 nations have signed the Convention and 119 have ratified it. Ratifying nations commit themselves to implement all obligations of the Convention. The CRPD is the first disability-specific international treaty and the first treaty to adopt the human rights approach to disability. ${ }^{7}$ Specifically, the CRPD promotes freedom of choice and autonomy, non-discrimination, full participation and inclusiveness in society, respect for the differences evident in persons with disabilities, equality of opportunity, accessibility to core social goods and services, and the identification and removal of barriers.

According to Article 12 of the convention, "persons with disabilities enjoy legal capacity on an equal basis with others in all aspects of life."1(p.9) The article states the need to "ensure that measures relating to the exercise of legal capacity respect the rights, will and preferences of the person, are free of conflict of interest and undue influence, are proportional and tailored to the person's circumstances." ${ }^{1(p .9)}$

Article 12 stresses the importance of supported decision-making, stating that all "parties shall take appropriate measures to provide access by persons with disabilities to the support they may require in exercising their legal capacity." ${ }^{1(\mathrm{p} .9)}$ As a result of Article 12, substitute/surrogate decisionmaking models - that is, the process by which decisions are made on behalf of adults who are judged to lack decision-making capacity-should be replaced with supported decision-making models and lead the care of people with ID. However, decision-making is not a simple task, and opportunities for decision-making are not always abundant. This article maps the current decision-making situation four years after the enactment of Article 12 which can be used as a base for comparison in future years. With this aim we conducted a systematic review of the literature on decision-making among individuals with ID since the CRPD has come into force in 2008. Studies related to decision-making within different domains of life are reviewed and challenges are described. Reviewing the literature only four years after the CRPD has come into force will allow us to map the current state of decision-making among individuals with ID in order to allow for changes in policy and practice that may advance achievement of the CRPD. 


\section{SEARCH STRATEGY}

Bibliographic databases, including ERIC, Web of Knowledge, PubMed, PsycNET, Social Science Research Network, and Social Services Abstracts, were used to search for manuscripts focusing on decision-making in ID. The search was conducted within the title or abstract of the manuscript using the following search terms: "intellectual disabilities," "supported decisionmaking," "substitute-decision making," and "decision-making." Manuscripts were limited to those published in English since 2008. A flow chart depicting the systematic review process that was utilized is presented in Figure 1. The search strategy yielded a total of 196 potentially relevant manuscripts. After removing duplicate manuscripts and manuscripts that were not found, 48 manuscripts that appeared to meet the inclusion criteria were examined for a more detailed evaluation. Nine articles were excluded, as they were review or position papers, and 13 were excluded for other reasons (a focus other than ID, a focus on the decision-making of individuals other than those with ID, or no specific focus on decision-making). Finally, 26 manuscripts were retained for the final review and one additional manuscript was added through hand-searching, yielding a total of 27 manuscripts.

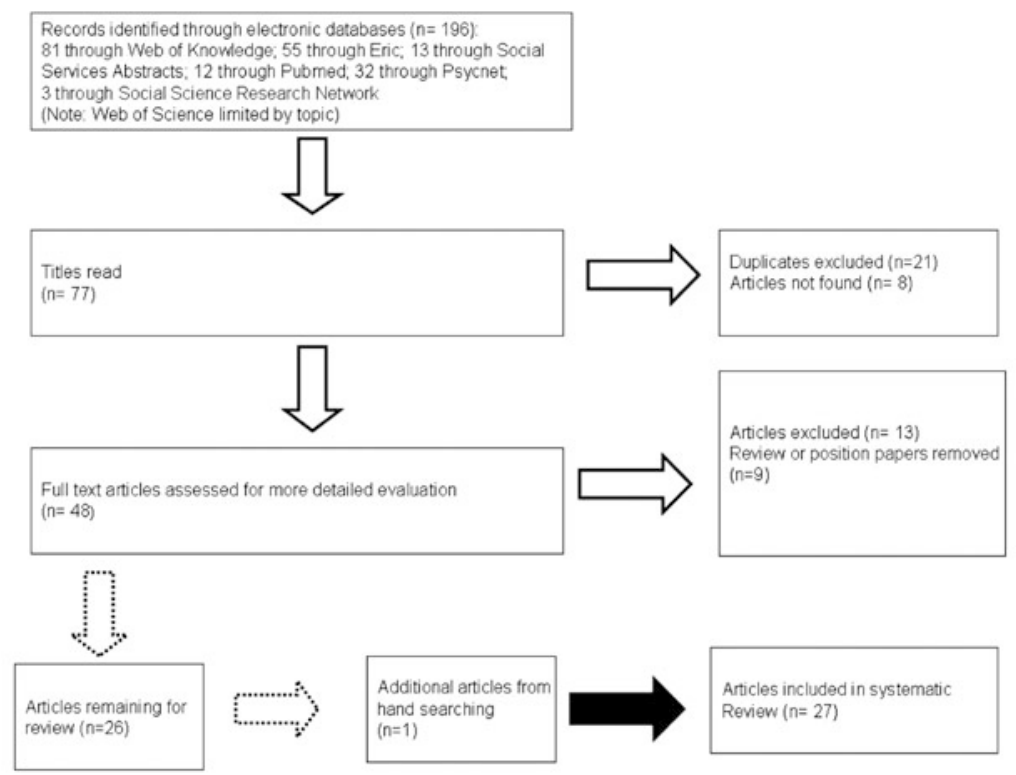

Fig. 1. Systematic review flow chart 


\section{ANALYSES OF MANUSCRIPTS}

Manuscripts were analyzed according to the following criteria: The content was examined for the specific decision-making field and challenges in decision-making. Further, I examined the legal and human rights framework on which the study was based. Specifically, I concentrated on whether the literature reviewed as background for the study mentioned the CRPD, or any other human rights legal document and if substitute or supported decision-making constructs were mentioned. Finally, given the obligations set forth in the CRPD for participation, inclusion, equality and nondiscrimination, the inclusion of people with ID in the research was examined, concentrating especially on whether people with ID were themselves the research participants, i.e., if their voice was heard rather than involving a proxy; and if they were involved as research partners.

\section{RESULTS}

\section{BACKGROUND OF REVIEWED MANUSCRIPTS}

Eleven manuscripts originated from the United Kingdom; eight from the United States; two from Australia and Taiwan; and one each from New Zealand, Canada, Ireland and the Netherlands. To date, the UK, Australia, New Zealand and Canada have signed and ratified the CRPD; the US, Ireland and Netherlands have signed the convention only; and Taiwan has neither signed nor ratified the convention. The reviewed manuscripts utilized different methodological designs: seven with questionnaires or surveys, three with automated computer tasks, and 17 with a variety of qualitative methods.

\section{DECISION-MAKING FIELDS}

The studies examined in this review focused on decisions within different contexts, including: transition to adulthood, self-advocacy, residential settings, employment, health care, sexuality and pregnancy and research participation. The use of a human-rights framework and surrogate or substituted decision-making is discussed within each field (for more details, see Table 1). A discussion on the inclusion of individuals with ID in the research will be presented within the discussion section. 


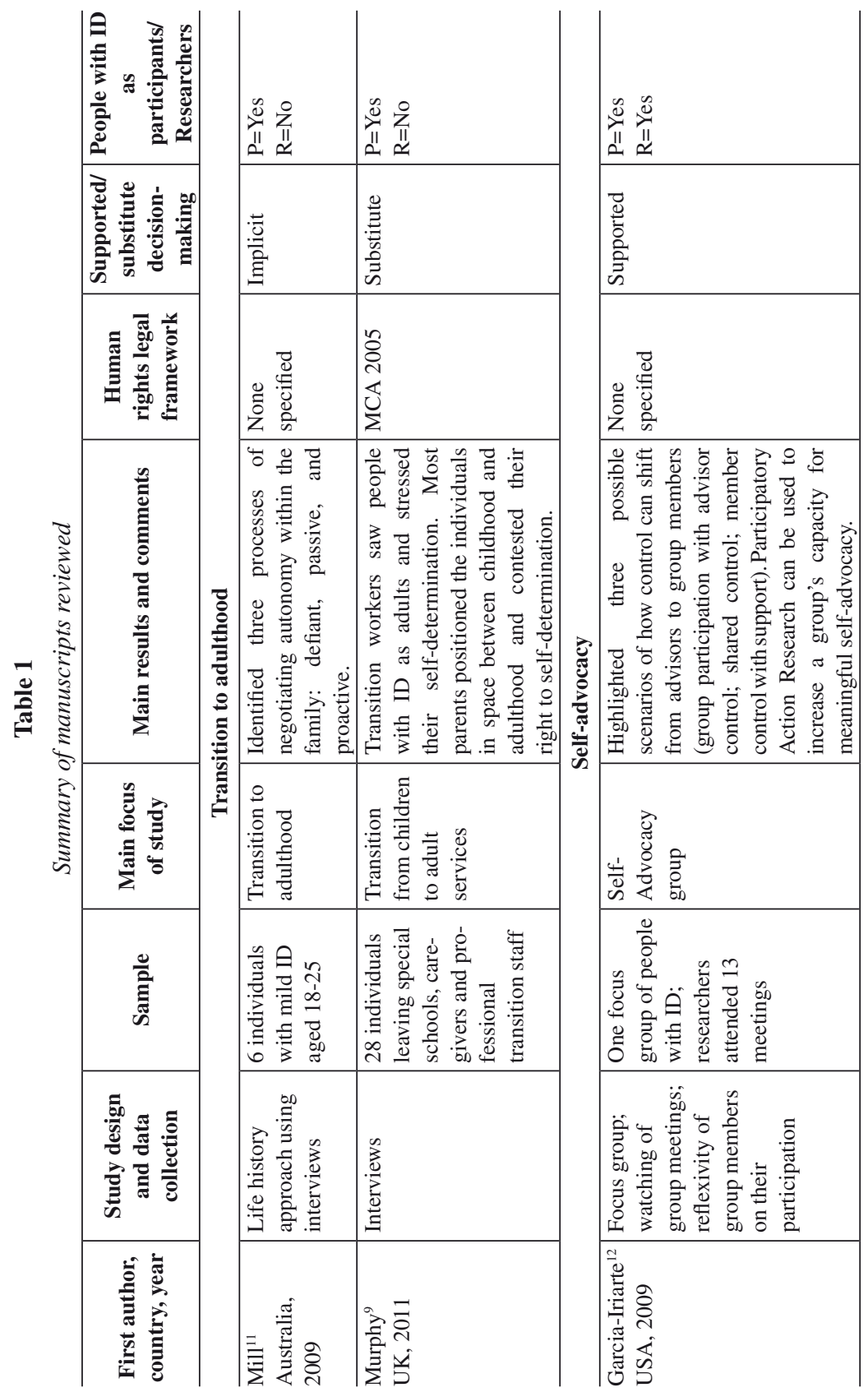




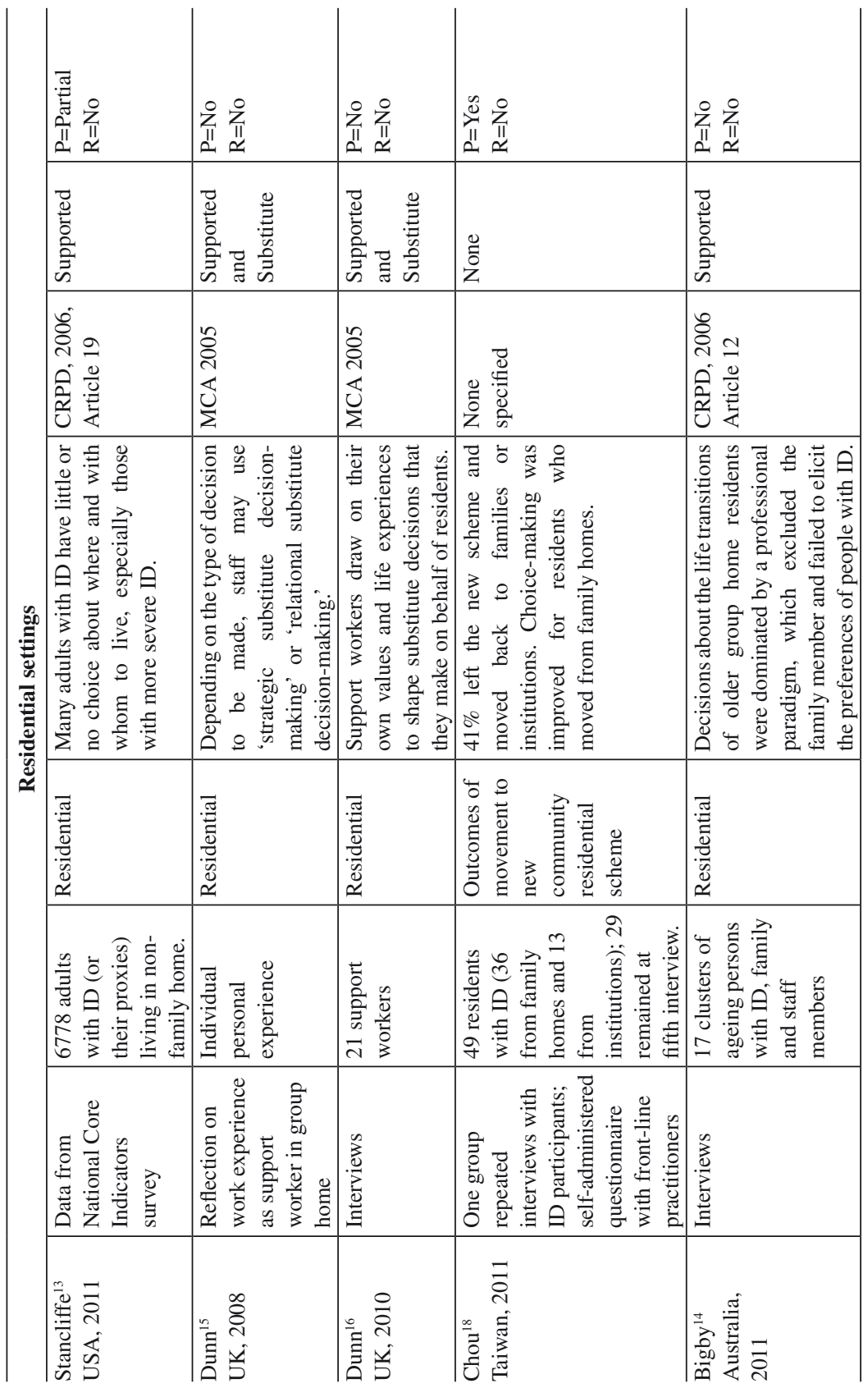




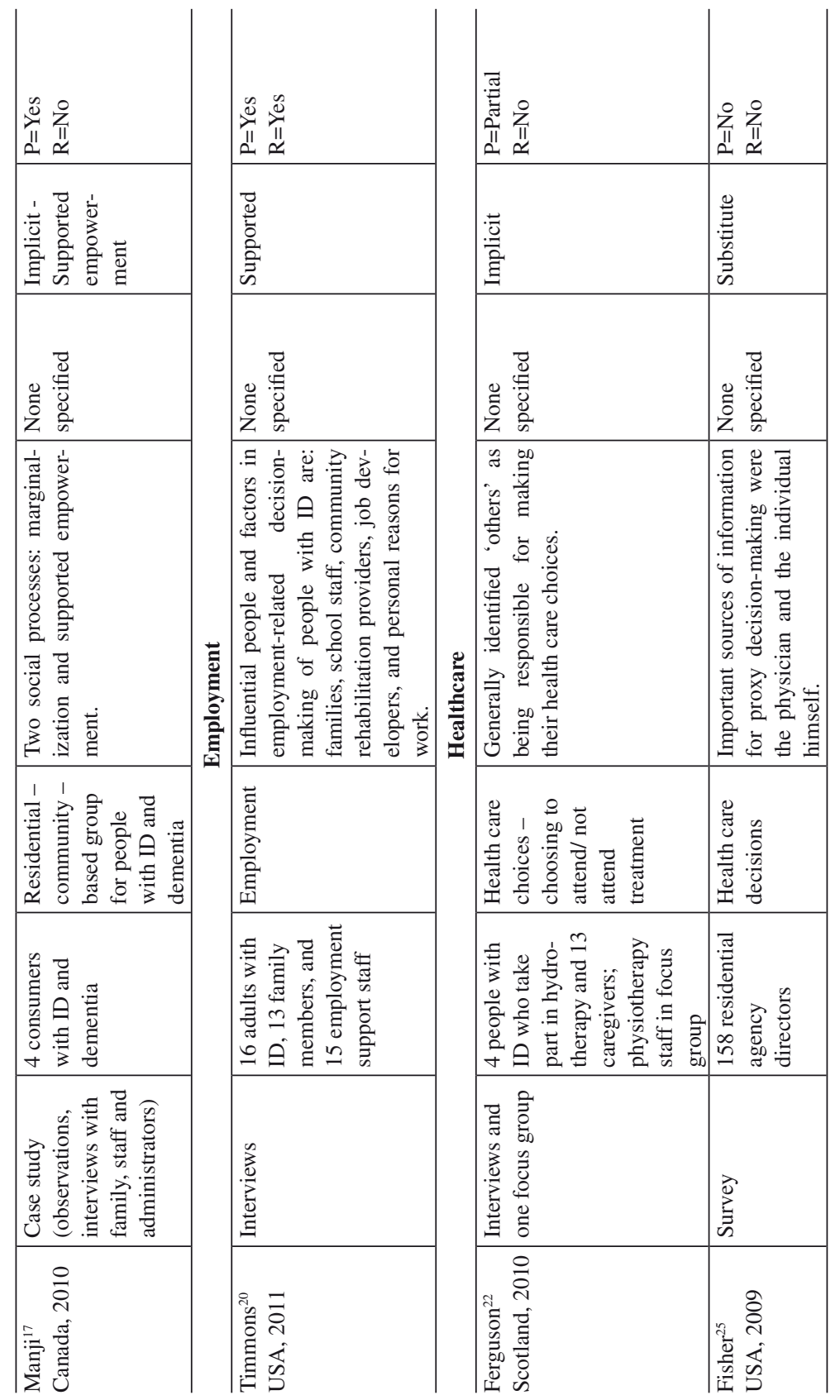




\begin{tabular}{|c|c|c|c|c|c|}
\hline$\sum_{\substack{\| \\
\Perp}}^{0}$ & $\sum_{\substack{11 \\
\Perp}}^{0}$ & & 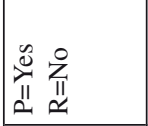 & 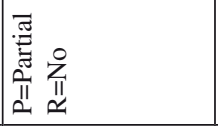 & 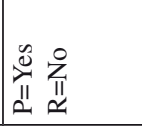 \\
\hline & 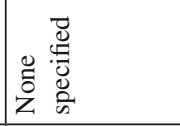 & & 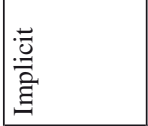 & 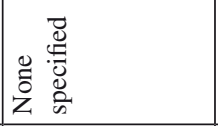 & 莺 \\
\hline 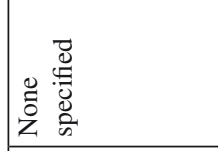 & 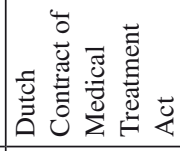 & & 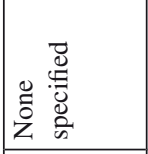 & 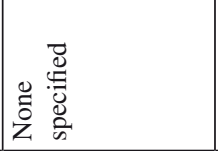 & 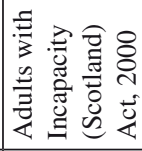 \\
\hline 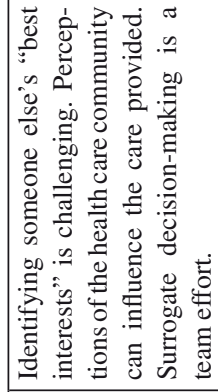 & 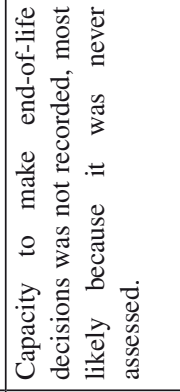 & 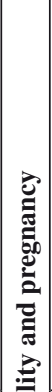 & 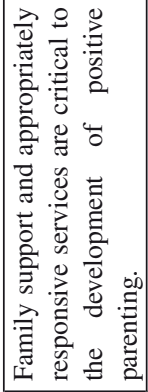 & 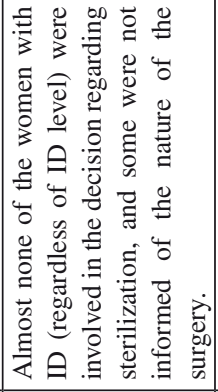 & 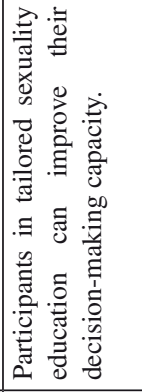 \\
\hline 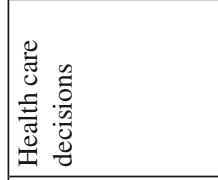 & 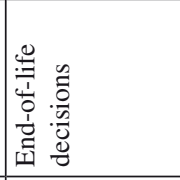 & 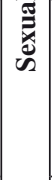 & 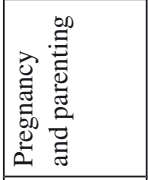 & 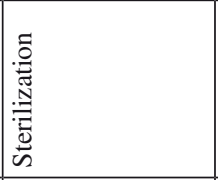 & 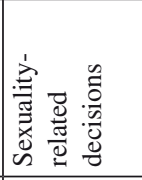 \\
\hline 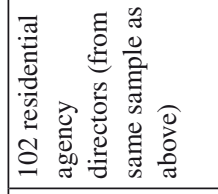 & 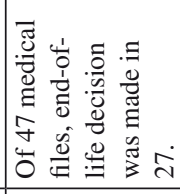 & & 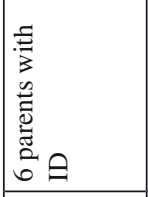 & 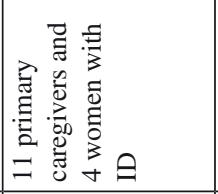 & 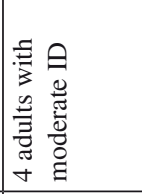 \\
\hline 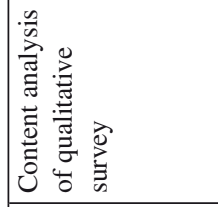 & 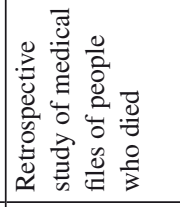 & & 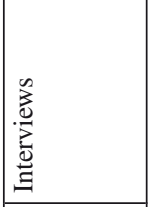 & 恣 & 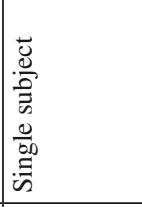 \\
\hline 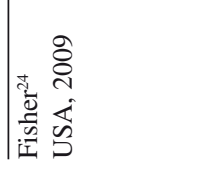 & 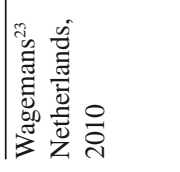 & & 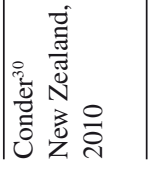 & 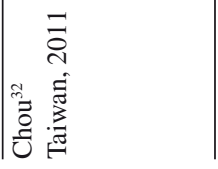 & 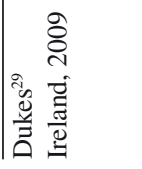 \\
\hline
\end{tabular}




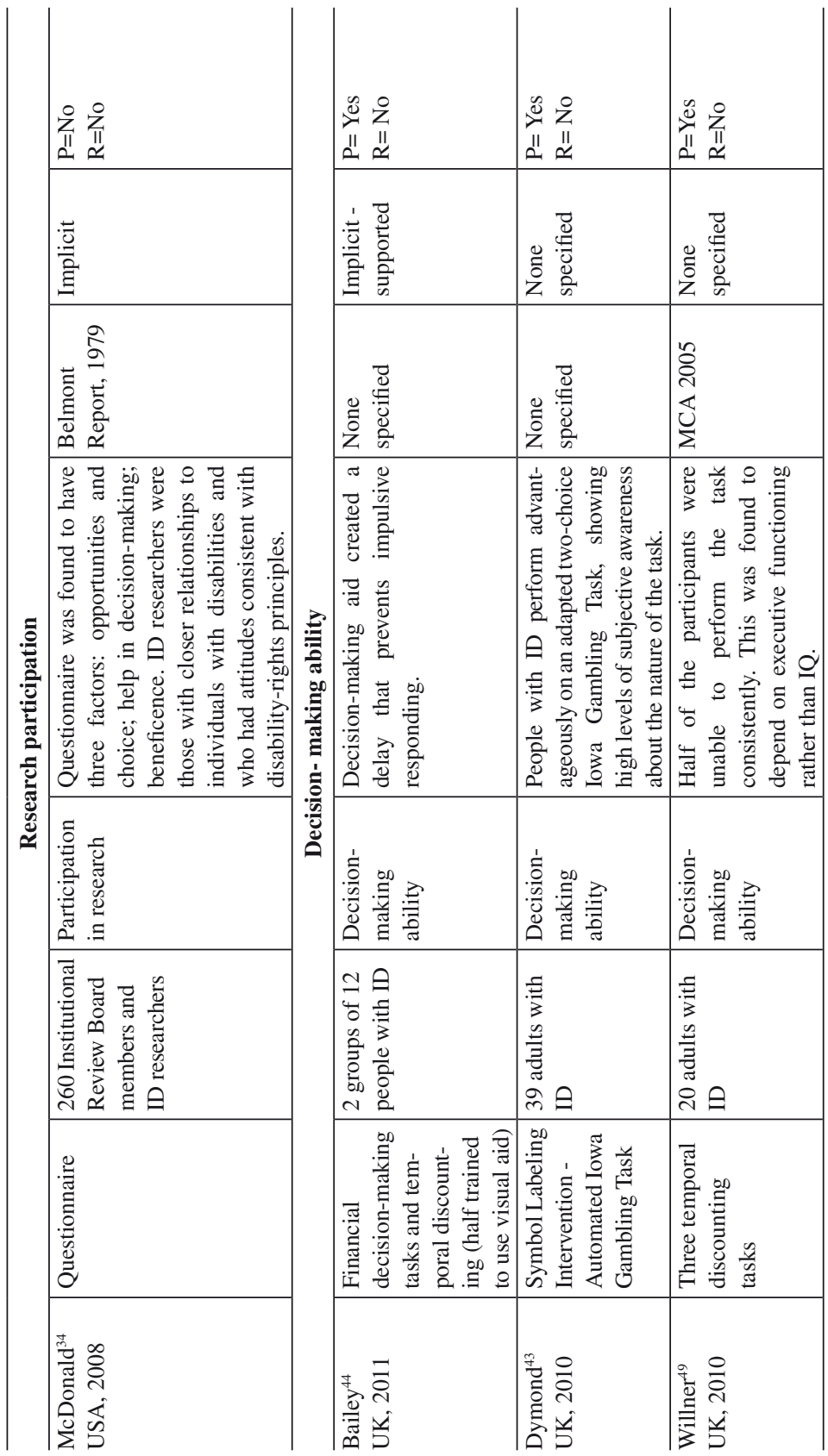




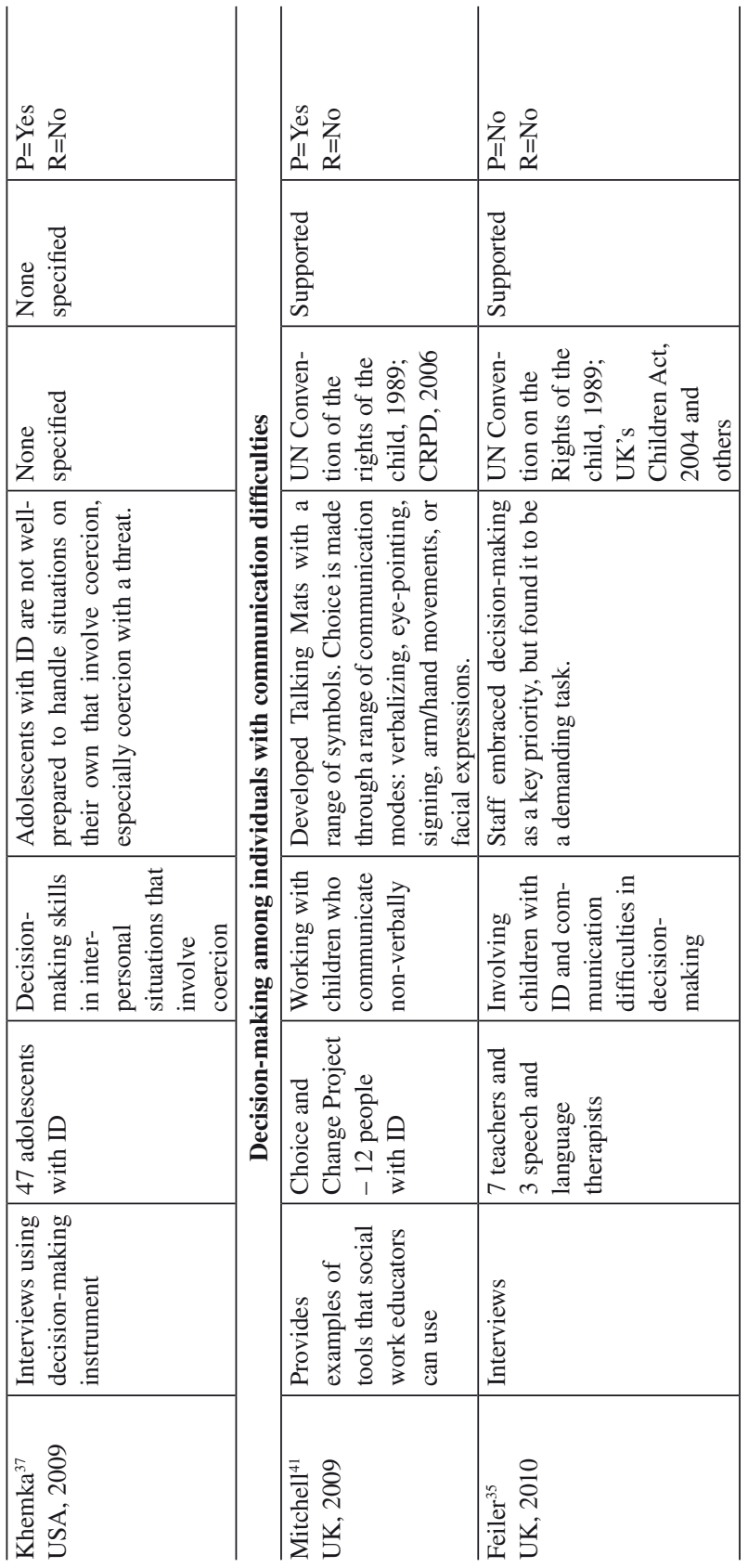




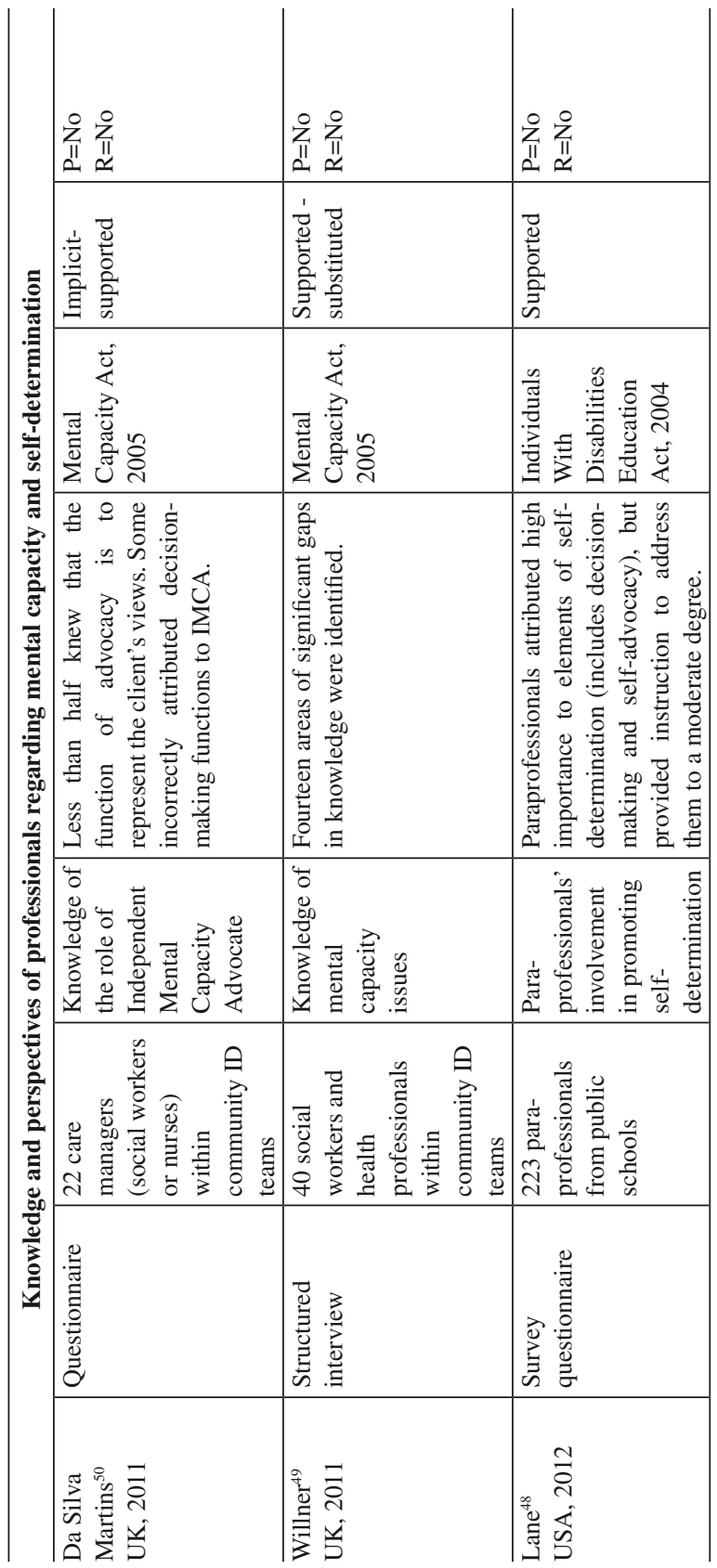




\section{Transition to adulthood}

Adulthood brings with it increased autonomy and the ability to be a causal agent in one's own life. ${ }^{8}$ In this review, only two qualitative studies focused on decision-making during the transition to adulthood. One of the articles ${ }^{9}$ was framed within UK's Mental Capacity Act 2005 (MCA) ${ }^{10}$ while the other did not regard a specific human-rights act. ${ }^{11}$ The MCA makes a legal presumption in favor of capacity and increased autonomy of people with ID, aims to increase choice and recognizes that capacity can fluctuate over time and is decision-specific. When decision-making capacity is lacking, decisions, according to the MCA, must be made in the best interest of the individual. Both studies clearly highlighted the need to support selfdetermination and choice ${ }^{9}$ and regarded adults with ID as experts of their needs. ${ }^{11}$ The first study implicitly supported the use of supported decisionmaking, while the second focused more on substituted decision-making.

The first showed that adults with mild ID differed in the extent to which they seek increased autonomy and the extent to which they perceived their parents to be supportive of their autonomy. The findings showed that young people with ID can indeed express their views by adopting a proactive approach, given the right environment and opportunity. ${ }^{9}$

The second study ${ }^{11}$ focused on the transition from children to adult services and its implications for decision-making. Despite advocating for self-determination, parents pointed to their children's dependence, vulnerability, and limited capacity for understanding consequences. Some professionals also had their own idea of what was a "good choice," and thus not all choices made by individuals with ID were considered to be legitimate. Given these results, the authors suggested that professionals have a responsibility to engage both people with ID and their families in determining the best choices for them.

\section{Self-advocacy}

One way to increase decision-making is through advocacy groups which empower service-users to speak out, assert themselves, and make their needs and wants known. One study explored how decisions were made within a People First* self-advocacy group for individuals with ID. Findings showed that the participation of group members depended upon opportunities to share ideas and feelings, provide input, and be involved in meetings. Various levels of support were considered to be important for participation,

\footnotetext{
* http://peoplefirstltd.com/ (accessed 28 September 2012).
} 
including member support, advisor support, and system support. ${ }^{12}$ Although the study did not clearly highlight a human-rights document, supported decision-making was clearly highlighted through the vision of self-advocacy and the participation of individuals with ID within the research team itself.

\section{Residential settings}

Six of the reviewed studies focused on decision-making in residential settings. Four of these studies acknowledged the importance of a humanrights framework via the CRPD ${ }^{13,14}$ or the MCA..$^{15,16}$ While all four stressed supported decision-making, studies based on the MCA also supported substituted decision-making, by use of the 'best-interest' checklist, in those cases that individuals lack decision-making capacity.

One central issue in the residential field relates to opportunities provided to individuals to choose where and with whom they would like to live. One study, asserted that individuals should participate in living choices regardless of the severity of the ID. ${ }^{13}$ However, fewer than half of nearly 7000 adults with ID in the US have actually been given the opportunity to exercise a choice about where or with whom to live. Individuals with milder ID were found to have more choices, especially if they lived on their own or in a sheltered apartment, while they had fewer choices if they lived in an institution or in a group home. Individuals with more severe ID had the least amount of choice, regardless of residence type. ${ }^{13}$

Two studies focused on decision-making among ageing persons with ID $^{14}$ or persons with ID and dementia. ${ }^{17}$ Findings from a study focusing on the transition into aged care showed that rather than respecting the rights of people with ID and viewing their needs and preferences as paramount, resource and organizational issues stemming from an ill-prepared system were responsible for shaping many of the decisions. ${ }^{14}$ Differently, a case study conducted within a unique group home for people with ID and dementia while not specifically citing a human-rights document, generated a theory of "supported empowerment" by which consumers can be empowered by practices of maintaining selfhood, freedom of choice, and active participation in the community. ${ }^{17}$

In Taiwan, improved decision-making was found among residents with ID who had moved away from their families, which suggests that residential services provided more autonomous living. However, many subsequently moved back to their families or institutions. ${ }^{18}$ Additionally, this study did not mention any human-rights nor supported decision-making approaches. This may be understood by the fact that Taiwan is not signed on the CRPD. 
Two studies examined substitute decision-making within the residential context. In line with the MCA,${ }^{10}$ 'strategic decision-making' was used for 'life plan' decisions and for health care interventions within a group home. However, 'everyday' personal and social interventions connected with the residents' daily lives were based on 'relational substitute decision-making' within a framework of interpersonal care relationships. ${ }^{15}$ Likewise, interviews with 21 support workers showed that they used their personal lives as a starting point to make substitute decisions on behalf of their residents. This approach was found to be problematic because the workers gave primacy to their own values and life experiences rather than to the residents' lives and needs. ${ }^{16}$

\section{Employment decisions}

As in the residential context, decision-making in the employment field is often driven by low expectations, funding restrictions, service delivery practices, and lack of information, rather than by individuals' own choices. ${ }^{19}$ The only empirical study found for this review in the employment context $\mathrm{t}^{20}$ examined the factors that influence employment decisions for people with ID by interviewing adults with ID, their family members, and support staff. Although this study did not specifically mention a human rights document, the importance of supported decision-making was made clear through the conclusion that increased education and resources can improve selfdetermination. Additional recommendations included: family members' engagement throughout the job search and planning process, building stronger links between schools and the employment system, changing negative assumptions about an individual's readiness to work in the community, offering a selection of jobs and supporting individuals to make friendships in community workplaces. Finally, the value of self-determination was seen through the participation of individuals with ID in the research team.

\section{Health care decisions}

Four studies focused on decision-making within the health care field. Selfdetermination and the active involvement in and management of one's own health is important to improving the health and wellness of people with ID. ${ }^{21}$ Unfortunately, studies showed that the involvement of people with ID in health care decisions was limited. Most of the studies did not mention a human-rights framework, although one made the case that choice agenda was part of the policy in Scotland. ${ }^{22}$ The other studies ${ }^{23-25}$ focused on substituted decision-making stressing that these decisions need to be made on behalf of the individual. For example, Ferguson, et al. ${ }^{22}$ showed that people with ID 
demonstrated some understanding of choice and were involved in a number of everyday decisions. However, caregivers questioned their capacity to make health care decisions. Thus, the decisions to attend health care appointments were primarily made for, or in a few instances with, people with ID. ${ }^{22}$

Similarly, the involvement of people with ID in end-of-life decisions was also found to be low. In a retrospective study of the medical files of deceased individuals, family members were found to be involved in end-oflife decision-making in about half of the cases, while no formal representative was involved in the other cases. The files examined did not include information about the views of the people with ID themselves or about their capacity to make an end-of-life decision. Furthermore, the decisions made were not discussed with the individual. ${ }^{23}$ Nevertheless, it is important to acknowledge that, end-of-life decisions are difficult regardless of ID as seen by the finding that in the Netherlands (where the above study took place) communication between doctor and patient took place in only 38 percent of general end-of-life decisions. However, the situation in ID was worse as communication did not take place in any of the cases. ${ }^{23}$

Although substituted decision-making was frequently used, studies also described the difficulties in this role. For example, in the previous study regarding end-of-life decisions, the authors pointed to a worrying possibility that parents' biased decisions may be discriminatory or lead to unethical practice. ${ }^{23}$ Similarly, in the US, two studies ${ }^{24,25}$ highlighted the challenge in identifying the "best interests" of a person with ID, as they involve a value judgment about what matters most. Importantly, the choice process could be influenced by how the options are presented and reinforced, such that subtle or even coercive influences may be used to achieve the "right" choice as viewed by other interested parties. ${ }^{26}$ Thus, the presentation of choices needs to be adapted to meet the needs of the individuals. ${ }^{22}$ Additionally, decisions should be carefully considered by a range of caregivers and professionals. ${ }^{24}$

\section{Sexuality and pregnancy}

Individuals with ID have the same needs for intimate relationships and sexual expression as everyone else. ${ }^{27}$ Adults are considered to have the capacity for sexual consent if the required rationality, knowledge, and voluntariness are present. ${ }^{28}$ Only one of the three articles found in this life domain ${ }^{29}$ made a specific regard to a human-rights document, the Adults with Incapacity (Scotland) Act 2000. This Act was used to make the case that capacity is not static and can be improved. Individually tailored sex education programs could improve supported decision-making by regarding sexuality, ${ }^{29}$ pregnancy and parenting, ${ }^{30}$ thus improving autonomous decision-making abilities. ${ }^{29}$ 
Contrary to these studies, a recent review ${ }^{31}$ showed that individuals with ID encountered difficulties in exercising their full sexual autonomy due to social and environmental barriers. In cases of sterilization and hysterectomy, in Taiwan, the autonomy of women with ID was constrained by their families and professionals, with no consideration for the essential human rights of the women. ${ }^{32}$ Furthermore, it seems that decision-making among individuals with ID may also depend, at least to some extent, on the social status of the individual as most married women who were sterilized came from relatively low socio-economic background. ${ }^{32}$ However, it should be noted that in the traditional society of Taiwan, reproduction decisions, regardless of ID, are considered to be a familial issue involving the man's parents. ${ }^{33}$ Furthermore, Taiwan has not signed and is therefore not bound to the CRPD.

\section{Decisions on participation on research}

Only one study focused on decision-making within the research field and examined the attitudes of Institutional Review Board members and ID researchers toward the research participation of adults with ID. This study was based on the guiding principles of the Belmont Report (1979) including respect for persons, beneficence and justice. Findings showed that participants who supported the general right of adults with ID to selfdetermination also endorsed their right to have opportunities to participate and make decisions in research settings. On the other hand, participants who advocated for the protection of adults with ID perceived a greater need for these individuals to receive support in making decisions about research participation. ${ }^{34}$

\section{CHALLENGES IN DECISION-MAKING AMONG INDIVIDUALS WITH ID}

The reviewed manuscripts elicited various challenges with regard to decision-making which may be related to the individuals with ID, to their professional caregivers and to the service system.

\section{Challenges related to the individual}

Individuals with ID face several challenges that threaten their capacity to make decisions. In a study examining decision-making when coercive tactics were used, ${ }^{37}$ the authors concluded that difficulties may arise in one or more of the following stages of the decision-making process: 1) framing 
of the situation; 2) generating possible alternative solutions; 3) evaluating potential consequences associated with each alternative; and 4) selecting a decision response..$^{38}$

One of the barriers is severity of ID, ${ }^{22}$ with difficulties in verbal and memory deficits, difficulties with problem-solving, a tendency towards acquiescence and suggestibility, problems with abstract thinking, and an overly concrete thought process. ${ }^{39}$ Although many individuals with ID have enough cognitive capacity in at least some components of the decisionmaking process ${ }^{40}$ individuals with severe ID may not be aware of their role in the decision-making process and the options available to them. ${ }^{22}$

Additionally, for people with ID, it is especially difficult to make decisions that are based on information from two sources, such as magnitude (e.g., sum of money) and delay (e.g., immediate versus delayed reward). ${ }^{41}$ This relates to problems in executive functioning, rather than IQ, which may underlie reasoning abilities in people with ID. Executive functioning refers to the complex set of cognitive processes that regulate an individual's ability to organize thoughts and activities, prioritize tasks, manage time efficiently, and make decisions. It includes goal-setting and planning, organization of behavior over time, response initiation, response inhibition, attention, working memory, set shifting and fluency. ${ }^{42}$

Communication difficulties pose an additional barrier to decisionmaking among individuals with ID by making it difficult for individuals to express their own needs. ${ }^{35}$ The vocabulary which adults provide for children may be too restricted and insufficiently individualized for individuals with communication difficulties. ${ }^{35}$

\section{Dealing with decision-making challenges by use of visual aids and assistive communication}

Three studies focused on how computerized visual aids may assist individuals with ID in making more advantageous decisions. As these studies focused on explaining and testing the utility of the aides; all but one $^{41}$ did not mention any human-rights act. Further, most made no specific regard to the need for substituted or supported decision-making. In these studies, a symbol labeling intervention ${ }^{43}$ and a visual aid ${ }^{44}$ significantly improved advantageous decision-making among people with ID and enabled participants to 'weigh-up' evidence through a richer consideration of pros and cons in financial decisions and temporal discounting. ${ }^{43}$ The authors asserted that after training, this visual aid may improve the ability to make choices in other daily tasks, ${ }^{41,44}$ which may point to the authors' awareness of the importance of supported decision-making. 
Visual aids have also been found to be important for children with ID and communication difficulties. Two studies that examined this area were framed deeply within a human rights framework including the CRPD, the UN Convention of the Rights of the Child (1989), and other UK policy initiatives which assert the importance of listening to a child and allowing them to make their choices. These policies endorse supported decisionmaking by using appropriate methods for listening to children with ID and non-verbal communication. ${ }^{35}$ For example, Mitchell, et al. ${ }^{45}$ described the use of Talking Mats*, which allow for the expression of choice from a range of symbols. According to this study, professionals need to make children with ID aware of the range of potential choices available and allow them sufficient time to respond when making decisions. ${ }^{35}$ These studies have emphasized the importance of individualized approaches based on a detailed understanding of children's needs. ${ }^{35}$

\section{Challenges related to professional caregivers}

The literature shows that some challenges to decision-making among people with ID are attributable to professional caregivers. The main challenge is that individuals are not always provided with the information and support required to meet their needs ${ }^{46}$ and may only be given restricted opportunities for decision-making. These difficulties can be understood in light of caregivers being wary about allowing too much choice, given the need to balance the rights of individuals to direct their own lives versus the personal, professional and ethical responsibility of the caregivers to make the "right" choice. ${ }^{47}$

Knowledge, training, and attitudes of professionals have been found to be predictive of their ability to support decision-making. Based on the US Individuals with Disabilities Education Act 2004, Lane, et al. ${ }^{48}$ found that more than 80 percent of paraprofessionals in the study rated decisionmaking as having a high instructional priority. Findings implicitly endorsed supported decision-making as the authors asserted the importance of providing meaningful opportunities to develop skills, attitudes and behaviors that enhance self-determination.

Two additional studies examined professionals' knowledge about the decision-making ability of individuals with ID based on the UK's MCA ${ }^{10,49,50}$ thus, referring to the importance of supported decision-making.

Based on this Act, Willner, et al. ${ }^{49}$ found gaps in knowledge among health and social service professionals within community ID teams, including a lack of knowledge that it was the responsibility of all professionals to exercise

\footnotetext{
* http://www.talkingmats.com/ (accessed 28 September 2012).
} 
their own judgment about their clients' decision-making capacity. The second study ${ }^{50}$ found that care managers did not have a clear understanding of the role of Independent Mental Capacity Advocates (IMCA), as only about half of them knew that their role was to represent the client's views. Furthermore, of nine decision-making scenarios presented, participants identified that an IMCA referral was called for in less than 50 percent of the cases.

\section{Challenges within the service system}

Many of the above challenges can also be understood as being rooted in the service system itself. For example, questions have been raised regarding the adequacy of training provided to professionals within services, such as MCA training ${ }^{50}$ or provision of training and familiarity with selfdetermination. ${ }^{48}$ Lack of training within services may also be related to large workloads and pressures which limit the ability of the service to commit to provision of training. ${ }^{49}$ Additional challenges included: limited opportunities for choice-making, or lack of flexibility in services, ${ }^{35}$ organizational difficulties, and an absence of relevant policies. ${ }^{14}$ Additionally, services may lack in resources including shortage in staffing ${ }^{14}$ and lack of availability of communication and visual aids to aid those individuals with ID and communication difficulties. ${ }^{36}$ These may lead to limited use of supported decision-making approaches and limited time that staff members can provide to each individual.

\section{DISCUSSION}

The aim of this article was to map the current state of decision-making among people with ID by reviewing the available research, four years after the CRPD entered into force in 2008. Decision-making among people with ID was found to be complex. The vast majority of published knowledge was found in the fields of residential services, health care decisions, and sexualityrelated decisions. Scant research has been conducted in other fields, such as employment, self-advocacy and research participation. Difficulties were related to the individuals with ID themselves, as well as to the caregivers in charge of supporting the decision-making process and service systems.

Since the CRPD entered into force relatively recently, it was not surprising that only three articles addressed it in their framework. These studies originated from the UK, US and Australia, and two of them focused on the field of residential care. As an international instrument, the CRPD does not replace domestic law, but rather serves as a supplement and an interpretive tool, depending on its status in each specific country. Local 
legislation therefore often serves as the legal framework of the analysis. For example, studies originating from England and Wales utilized the MCA as their legal framework. Similarly to the CRPD, the MCA assumes that adults with disabilities have capacity to make decisions (Part 1, Principle 2). Adults are not treated as unable to make a decision unless all practicable steps and support to help them to do so have been taken without success (Part 1, Principle 3). Further, according to the MCA, any decisions made on an individual's behalf must be in the individual's best interests (Part 1, Principle 5), ${ }^{51}$ although criticisms on the application of the best interest standard have been raised. ${ }^{52}$ In line with this, in Scotland, the Adults with Incapacity Act $2000^{53}$ regulates interventions in adults who may have impaired capacity. These interventions must be minimal and tailored to the individuals' needs using whatever aids, communication support or advocacy the individual may require. The references to these Acts in the above studies show that their authors appreciate the importance of protecting human rights in decision-making processes.

The findings of this review elicit several challenging questions such as: is supported decision-making among people with ID always possible? Is it possible to apply in all decision fields and also for people with more severe ID? The publications reviewed in our study showed that supported decisionmaking was more strongly endorsed in some fields (e.g., residential setting, employment and self-advocacy) and less in others (e.g., healthcare). One may conclude that in more complex and sensitive decisions, preference is given to caretakers' decisions. Another possibility is that in an acute stage of illness, an individual's capacity for decision-making may be hindered, regardless of ID. However, the second option most likely influenced only a minority of the cases.

While Article 12 of the CRPD places utmost value to supported decision-making, and places responsibility on caregivers, services, policy makers and researchers to find the way in which supported decision-making can be achieved for all individuals, it does not provide specific guidelines for achieving this and does not provide answers to situations in which individuals may be unable to take autonomous decisions. Consequently, the way of operationalizing and translating its recommendations is left blurred and undefined. Thus, it is not surprising that this review shows that, although some of the studies make recommendations on how to improve decision-making among this population, no study found presented comprehensive working models that can be used to guide and implement supported decision-making. This is one task at hand for the future. Without translating the recommendations of Article 12 into practical models that 
will guide the stakeholders responsible for the well being of individuals with ID, their autonomy will remain only expressed in the legal article.

Finally, the reviewed studies showed that rarely did individuals with ID participate as research partners in a collaborative research design, as only two studies had individuals with ID take some role in the research itself. Both of these were studies conducted in the US, one in the field of employment ${ }^{20}$ and the second in self-advocacy. ${ }^{20}$ The lack of incorporation of people with ID in the research may be indicative of their general stereotype as less competent and unable to state their wishes. Future research should encourage such collaboration which may bring about enhanced community inclusion and participation of this population group.

\section{LIMITATIONS OF THE REVIEW}

The results of this review should be considered in light of several limitations. First, Despite making every attempt to unearth the relevant literature, we cannot disregard the possibility that some studies may not have been identified. This is an inherent limitation of systematic reviews, which in an effort to be specific are prone to miss papers of importance. ${ }^{54}$ Second, the review is limited to published research and may not be exhaustive of the unpublished approaches utilized by ID services. Thus, I urge ID services to devote more time to evaluation research in order to examine the efficacy of the methods which they employ. This is highly important in order to enhance knowledge in the field and increase the use of effective decisionmaking models. Third, only four years have passed since the implementation of the CRPD. Thus, some of the studies cited may have actually been conducted prior to the CRPD. An additional review should be conducted in about five years in order to map the change during this time. This five year time-frame will allow researchers to examine if and how the CRPD has come to be employed within service system practice guidelines and curricula for professional care. Finally, most studies reviewed did not examine difference in choice-making as it relates to socio-economic status of the individual. It would be interesting for future studies to examine the possible existence of a social gradient to decision-making participation.

\section{CONCLUSIONS AND IMPLICATIONS}

In sum, this review shows that supported decision-making is still lacking in various decision-making fields for individuals with ID. Its findings have 
conceptual and practical implications. Conceptually, this review blends two separate but interrelated perspectives - the public health and human rights perspectives. From the public health perspective, ID is a condition that should be investigated and monitored. From the human rights perspective, the focus is on dignity for all persons with disabilities and the need for policies to ensure the equal rights of these persons. The present review joins recent efforts to see these perspectives as complementary. ${ }^{55}$

Practically, this review stresses the need to improve supported decisionmaking for individuals with ID. For example, in addition to the need to develop supported decision-making models for use in the health, social welfare and education sectors, this review highlights several recommendations. First, training and education must be provided to persons with ID in order to help them develop better decision-making skills. ${ }^{56}$ This process includes teaching them elements of goal planning and selfregulation so as to encourage greater self-determination and actualization of their values. ${ }^{19}$ One-to-one educational interventions need to take into account the impact of cognitive disabilities and should be matched to the learning style, skills and abilities of the individual learner. ${ }^{29}$

Second, services must be tailored to allow for true choice and selfdetermination. A larger workforce is needed as well as some flexibility in daily routine to fit with individuals' choices. This can be achieved through person-centered planning, which involves understanding individuals' specific dreams and aspirations and creating the conditions that will promote them. ${ }^{57}$ Additionally, policies and practices, such as consumer direction in services, the support of self-advocacy movements and inclusion in decision-making, should be encouraged to help facilitate greater expression of self-determination. ${ }^{19}$

Third, caregivers (both family and professional) should be provided with the appropriate knowledge, skills and training in communicating with persons with ID in order to provide the needed support that will facilitate supported decision-making. Visual aids may be used in order to enhance the understanding of choices that will allow individuals with ID to make decisions. The main elements of true choice should be taught to caregivers, such as the need to focus less on the outcome and more on the process of decision-making. ${ }^{22}$ Furthermore, caregivers need to examine the individuals' ability to make a decision in each specific case, rather than as a general rule, and to accept that people with ID should be allowed to make mistakes as learning opportunities. ${ }^{55}$ Finally, caregivers must undergo adequate preparation to learn how to discuss certain topics which may cause them discomfort. 


\author{
Acronyms List: \\ CRPD $=$ UN Convention on the Rights of People with Disabilities \\ ID = Intellectual disabilities \\ IMCA = Independent Mental Capacity Advocates \\ MCA $=$ UK Mental Capacity Act 2005
}

Conflicts of Interest: None declared.

About the Author: Dr. Shirli Werner is a lecturer at the Paul Baerwald School of Social Work and Social Welfare at the Hebrew University of Jerusalem. Her main interest areas are in the field of intellectual disabilities and the dual diagnosis of intellectual and psychiatric disabilities. Dr. Werner is currently concentrated on two main and interrelated lines of inquiry. First, her research focuses on quality of life and family quality of life among families that have a member with an ID. Second, Dr. Werner also focuses on stigma in the area of intellectual disability and dual diagnosis.

\title{
REFERENCES
}

1. UN General Assembly: Convention on the Rights of Persons with Disabilities A/RES/61/106: Resolution. 24 January 2007. Available from URL: http:// www.unhcr.org/refworld/docid/45f973632.html (accessed 6 June 2012).

2. Schalock RL, Borthwich-Duffy SA, Bradley VJ, Buntinx WHE, Coulter EM, Craig EM, et al. Intellectual Disability: Definition, Classification, and Systems of Supports (11th edition). Washington DC: American Association on Intellectual and Developmental Disabilities; 2010.

3. Davis EL, Barnhill J, Saeed SYA. Treatment models for treating patients with combined mental illness and developmental disability. Psychiatr Q. 2008;79:205-23.

4. Lotan G, Ells C. Adults with intellectual and developmental disabilities and participation in decision making: ethical considerations for professionalclient practice. J Intellect Dev Disabil. 2010;48:112-25.

5. Neely-Barnes S, Marcenko M, Weber L. Does choice influence quality of life for people with mild intellectual disabilities? J Intellect Dev Disabil. 2008;46:12-26.

6. Harpur P. Embracing the new disability rights paradigm: the importance of the Convention on the Rights of Persons with Disabilities. Disabil Soc. 2012;1:1-14.

7. Kanter AS. There's no place like home: the right to live in the community for people with disabilities, under international law and the domestic laws of the United States and Israel. Isr Law Rev. 2012;4:181-233.

8. Wehmeyer ML, Bolding N. Enhanced self-determination of adults with intellectual disability as an outcome of moving to community-based work or living environments. J Intellect Disabil Res. 2001;45:371-83.

9. Murphy E, Clegg J, Almack K. Constructing adulthood in discussions about the futures of young people with moderate-profound intellectual disabilities. JARID. 2011;24:61-73. 
10. Mental Capacity Act. Office of Public Sector Information: London; 2005.

11. Mill A, Mayes S, McConnell D. Negotiating autonomy within the family: the experiences of young adults with intellectual disabilities. Br J Learn Disabil. 2009;38:194-200.

12. Garcia-Iriarte E, Kramer JC, Kramer JM, Hammel J. 'Who did what?': a participatory action research project to increase group capacity for advocacy. JARID. 2009;22:10-22.

13. Stancliffe RJ, Lakin KC, Larson S, Engler J, Taub S, Fortune J. Choice of living arrangements. J Intellect Disabil Res. 2011;55:746-62.

14. Bigby C, Bowers B, Webber R. Planning and decision making about the future care of older group home residents and transition to residential aged care. J Intellect Disabil Res. 2011;55:777-89.

15. Dunn MC, Clare ICH, Holland AJ. Substitute decision-making for adults with intellectual disabilities living in residential care: learning through experience. Health Care Anal. 2008;16:52-64.

16. Dunn MC, Clare CH, Holland AJ. Living 'a life like ours': support workers account of substitute decision-making in residential care homes for adults with intellectual disabilities. J Intellect Disabil Res. 2010;54:144-60.

17. Manji S, Dunn P. Supported empowerment for individuals with developmental disabilities and dementia. J Dev Disabil. 2010;16:44-52.

18. Chou YC, Pu C, Kröger T, Lee W, Chang S. Outcomes of a new residential scheme for adults with intellectual disabilities in Taiwan: a 2-year follow-up. J Intellect Disabil Res. 2011;55:823-31.

19. Heller T, Schindler A, Palmer SB, Wehmeyer ML, Parent W, Jenson R, et al. Self-determination across the life span: issues and gaps. Exceptionality. 2011;19:31-45.

20. Timmons JC, Hall AC, Bose J, Wolfe A, Winsor J. Choosing employment: factors that impact employment decisions for individuals with intellectual disability. J Intellect Dev Disabil. 2001;49:288-99.

21. Lennox N, Taylor M, Rey-Conde T, Bain C, Boyle FM, Purdie DM. Ask for it: development of a health advocacy intervention for adults with intellectual disability and their general practitioners. Health Promot Int. 2004;19:167-75.

22. Ferguson M, Jarrett D, Terras M. Inclusion in healthcare choices: the experiences of adults with learning disabilities. Br J Learn Disabil. 2010;39:73-83.

23. Wagemans A, van Schrojenstein Lantman-de-Valk H, Tuffrey-Wijne I, Widdershoven G, Curfs L. End-of-life decisions: an important theme in the care for people with intellectual disabilities. JIDR. 2010;54:516-24.

24. Fisher KM, Green MJ, Orkin FK, Chinchilli VM. A content analysis from a US statewide survey of memorable healthcare decisions for individuals with intellectual disability. J Intellect Dev Disabil. 2009;34:258-65.

25. Fisher KM, Orkin FK, Green MJ, Chinchilli VM, Bhattacharya A. Proxy healthcare decision-making for persons with intellectual disability: perspectives of residential-agency directors. J Intellect Dev Disabil. 2009;114:401-10. 
26. Heslop P, Flokes L, Rodgers J, Hillman SA. Informed decision-making by people with intellectual disabilities (ID) when taking psychotrophic medication? Step 1; the provision of information. J Intellect Disabil Res. 2004;48:471.

27. Eklund M, Ostman M. Belonging and doing: important factors for satisfaction with sexual relations as perceived by people with persistent mental illness. Int J Soc Psychiatry. 2010;56:336-47.

28. Lyden, M. Assessment of sexual consent capacity. Sex Disabil. 2007;25:3-20.

29. Dukes E, McGuire BE. Enhancing capacity to make sexuality-related decisions in people with an intellectual disability. J Intellect Disabil Res. 2009;53:727-34.

30. Conder J, Mirfin-Veitch B, Sanders J, Munford R. Planned pregnancy, planned parenting: enabling choice for adults with a learning disability. Br J of Learn Disabil. 2010;39:105-12.

31. McGuire BE, Bayley AA. Relationships, sexuality and decision-making capacity in people with an intellectual disability. Curr Opin Psychiatry. 2011;24:398-402.

32. Chou YC, Lu ZY. Deciding about sterilization: perspectives from women with an intellectual disability and their families in Taiwan. J Intellect Disabil Res. 2011;55:63-74.

33. Ko NY, Muecke M. Reproductive decision-making among HIV-positive couples in Taiwan. J Nurs Scholarsh. 2005;37:41-7.

34. McDonald KE, Keys CB, Henry DB. Gatekeepers of science: attitudes toward the research participation of adults with intellectual disability. Am J Ment Retard. 2008;113:466-78.

35. Feiler A, Watson D. Involving children with learning and communication difficulties: the perspectives of teachers, speech and language therapists and teaching assistants. Br J Learn Disabil. 2010;39:113-20.

36. Hodge, S. What is the potential of augmentative and alternative communication not being realized? Exploring the experiences of people who use communication aids. Disabil Soc. 2007;22:457-71.

37. Khemka I, Hickson L, Casella M, Accetturi N, Rooney ME. Impact of coercive tactics on the decision-making of adolescents with intellectual disabilities. JIDR. 2009;53:353-62.

38. Khemka I, Hickson L. The role of motivation in the decision making of adolescents with mental retardation. In: Switzky HN, (editor). International Review of Research in Mental Retardation. Amsterdam: Elsevier; 2006. p.199-255.

39. Lyden M. Capacity issues related to healthcare proxy. Ment Retard. 2006;44:272-82.

40. Wong JG, Clare ICH, Holland AJ, Watson PC, Gunn M. The capacity of people with a 'mental disability' to make a health care decision. Psychol Med. 2000;30:295-306.

41. Willner P, Bailey R, Parry R, Dymond S. Performance in temporal discounting tasks by people with intellectual disabilities reveals difficulties in decisionmaking and impulse control. AJIDD. 2010;115:157-71. 
42. Meltzer L. Executive function: Theoretical and conceptual frameworks. In: Meltzer L, (editor). Executive Function in Education: From Theory to Practice. New York, NY: Guilford Press; 2007. p.1-3.

43. Dymond S, Bailey R, Willner P, Parry R. Symbol labeling improves advantageous decision-making on the Iowa Gambling Task in people with intellectual disabilities. Res Dev Disabil. 2010;31:536-44.

44. Bailey R, Willner P, Dymond S. A visual aid to decision-making for people with intellectual disabilities. Res Dev Disabil. 2011;32:37-46.

45. Mitchell W, Franklin A, Greco V, Bell M. Working with children with learning disabilities and/ or who communicate non-verbally: research experiences and their implications for social work education, increased participation and social inclusion. Soc Work Edu. 2009;28:309-24.

46. Freedman RI, Chassler D. Physical and behavioral health of adults with mental retardation across residential settings. Public Health Rep. 2004;119:401-8.

47. Brown I, Brown RI. Quality of Life and Disability: An Approach for Community Practitioners. London: Jessica Kingsley Publishers Ltd; 2003.

48. Lane KL, Carter EW, Sisco L. Paraprofessional involvement in selfdetermination instruction for students with high-incidence disabilities. EC. 2012;78:237-51.

49. Willner P, Jenkins R, Rees P, Griffiths VJ, John E. Knowledge of mental capacity issues in community teams for adults with learning disabilities. JARID. 2011;24:159-71.

50. Da Silva Martins C, Willner P, Brown A, Jenkins R. Knowledge of advocacy options within services for people with learning disabilities. JARID. 2011;24:274-9.

51. United Kingdom initial report on the United Nations Convention on the Rights of Persons with Disability. Office for Disability Issues. UK: HM Government; 2011. Available from URL: http://odi.dwp.gov.uk/docs/disabled-people-andlegislation/uk-initial-report.pdf (accessed 10 August 2012).

52. Szerletics A. Best interests decision-making under the Mental Capacity Act Essex Autonomy Project Green Paper Report. University of Essex: Essex Autonomy Project; 2011. Available from URL: http://autonomy.essex.ac.uk/ best-interests-decision-making-under-the-mental-capacity-act (accessed 20 September 2012).

53. Adults with Incapacity (Scotland) Act (2000). A briefing paper for voluntary sector service providers. Scotland.

54. Crowther MA, Cook DJ. Trials and tribulations of systematic reviews and metaanalyses. Hematology. 2007;1:493-7.

55. Gruskin S. Ethics, human rights, and public health. Am J Public Health. 2002;92:698.

56. Brown I, Brown RI. Choice as an aspect of quality of life for people with intellectual disabilities. JPPID. 2009;6:11-8.

57. Holburn S, Cea CD. Excessive positivism in person-centered planning. Research and practice for persons with severe disabilities. 2007;32:167-72. 